\title{
PAPELES DE ZAFIRO: SIGNOS POLÍTICO-MITOLÓGICOS EN LA VIDA ES SUEÑO
}

\author{
Frederick A. de Armas \\ University of Chicago \\ [Anuario calderoniano (ISSN: 1888-8046), 2, 2009, pp. 75-96]
}

Los escritores muchas veces se equivocan acerca de la futura fama de sus obras. Mientras que Cervantes se equivocó al pensar que sería recordado por su Persiles, Calderón fue mejor profeta. Usó el término «dama duende» en nueve de sus obras para mostrar la importancia de esta comedia - y realmente ha tenido éxito a través de los siglos. De igual importancia es el hecho de que incluyó La vida es sueño como la primera obra en el primer volumen de su teatro (1636). Además, la alegorizó en autos sacramentales. El juicio de Calderón ha resultado correcto, ya que, como explica Henry Sullivan, La vida es sueño fue más popular que los dramas de Shakespeare en ciertas épocas y en algunos países europeos ${ }^{1}$.

${ }^{1}$ Al estudiar la obra debemos de tener en cuenta que existen dos versiones como explica Ruano de la Haza en su introducción. La primera escrita entre 1627 y 1629 (yo diría después de 1630), y la segunda publicada en 1636. La hipótesis de Ruano nos lleva a aceptar que un pasaje del Castigo sin venganza de Lope alude a la obra cal- 
Aunque hoy día aceptamos la centralidad de La vida es sueño, podría haber sido algo inusitado en su época el hecho de que Calderón seleccionara esta obra como su texto preferido. Primeramente, es dificil de catalogar la obra, no siendo (para algunos) típica del teatro aurisecular. Hay quienes la llaman comedia filosófica, otros piensan que es comedia palatina, mientras que toda una serie de estudios han criticado la mezcla de un ambiente eminentemente trágico que resalta la importancia del hado, con la acción secundaria de Rosaura. Para Melveena McKendrick, las peripecias de Rosaura son parte de un tipo muy particular de comedia de capa y espada: «The plays with a maiden errant in search of a recalcitrant lover are too numerous to mention. The intention is to make the gallant consent to marry her» ${ }^{2}$. La mujer vestida de hombre por esta u otras razones, recuerda obras tales como El anzuelo de Fenisa de Lope de Vega, Don Gil de las calzas verdes de Tirso y Amar sin saber a quién del mismo Calderón. Haciendo eco de las interpretaciones inglesas de la época de la reina Victoria, donde se consideraba la obra como algo "wild» que tenía que ser domado ${ }^{3}$, afirmó Menéndez Pelayo que lo de Rosaura era: «una intriga extraña, completamente pegadiza y exótica que enreda a todo el drama como una planta parásita» ${ }^{4}$. Más que conocidas son sus palabras ya que causaron una reacción intensa por parte de la escuela británica de calderonistas y por otros críticos que utilizan la mitología o el platonismo para subrayar la unidad temática de la obra ${ }^{5}$.

deroniana (1992, p. 9). Ignacio Arellano también piensa que la primera versión no puede ser tan temprana: «No me parece verosímil que una comedia de Calderón, y menos de la entidad de La vida es sueño permaneciese varios años sin representarse, o que si se representara no tengamos noticia alguna de su recepción» (2001, p. 75).

2 McKendrick, 1974, p. 133.

${ }^{3}$ A pesar de su crítica y de sus intentos de «domar» la obra, FitzGerald, en su versión de La vida es sueño, caracteriza a Rosaura como figura que guía al protagonista. FitzGerald también recalca el hecho de que las acciones de Rosaura sirven de paralelo a las de Segismundo. Ver Borchard (2004) y mi estudio «Rosaura Subdued» (1987).

${ }^{4}$ Menéndez Pelayo, 1910, p. 278.

5 Recordemos los artículos de Sloman (1965), Whitby (1965) y Wilson (1965), junto con los acercamientos platónicos de Sciacca (19509, Sturm (1974) y Cope (1971). Para una definición de esta escuela británica de calderonistas y para una historia de su primera dispersión ver Pring-Mill, 1968. 
Pero para mí, lo que más distancia el texto de La vida es sueño de otros de su época es su compleja utilización de elementos mitológicos y astrológicos con los que la obra parece adquirir tintes paganos y hasta heterodoxos. Hay quienes han cuestionado tal visión, proponiendo que estoy convirtiendo a Calderón en un pagano ${ }^{6}$. Mi respuesta es triple. Primero, se ha dicho tanto de un Calderón católico y ortodoxo que vale la pena encontrar las brechas textuales que cuestionan tal interpretación. Segundo, creo que no puede haber duda del interés de Calderón en los textos y mitos clásicos — comenzando con sus muchas comedias palaciegas de sujeto mitológico y continuando con una serie de autos sacramentales que transforman mitos paganos en celebraciones cristianas de la eucaristía. Creo que hay más aquí que una simple apropiación de mitos a través de la alegoría y no que esto pueda explicarse como mero sincretismo. Ya desde los primeros años de la cristiandad los padres de la Iglesia como San Jerónimo se quejaban del conflicto de conciencia entre el deseo por la belleza de los clásicos greco-romanos y la contaminación que estos podían causar. Cuánto más existiría este conflicto después del Renacimiento y durante la Contra-Reforma. Así creo que en Calderón este conflicto debe ser subrayado.Y en tercer lugar, creo que hay algo aún más complejo en los textos calderonianos. Estos elementos mitológicos y astrológicos sirven además para esconder un subtexto político, una visión de España bajo Felipe IV7. La mitología y la astrología, entonces, se utilizan en parte como códigos o cifras que ayudan al auditorio letrado a comprender elementos que no pueden proclamarse directamente. A esto se refería Bances Candamo cuando decía que toda la crítica en la comedia debe hacerse con un $"$ decir sin decir» ${ }^{8}$. Estudiando el teatro de Lope de Vega, Melveena McKendrick muestra que existe un cierto decoro o cortesía por parte del poeta al uti-

${ }^{6}$ En una conferencia en Texas Tech University en 1981, Henry Sullivan preguntó por qué estaba tratando de convertir a Calderón en escritor pagano.

7 Podemos encontrar este subtexto, por ejemplo, en La dama duende y en El mayor encanto, amor.

${ }^{8}$ Según Bances Candamo «son las comedias de los reyes unas historias vivas que, sin hablar con ellos, les han de instruir con tal respecto que sea su misma razón quien de lo que ve tome las advertencias, y no el ingenio quien se las diga. Para este decir sin decir, ¿quién dudará que sea menester gran arte?» (Teatro de los teatros, p. 57). 
lizar técnicas de distanciamiento en la crítica política ${ }^{9}$. En este estudio quisiera revisar y repensar algunos de mis antiguos estudios para llegar a comprender mejor los códigos calderonianos. Hago esto teniendo muy en cuenta la advertencia de Ignacio Arellano, sobre el exceso de interpretaciones ideológicas de la comedia aurisecular: «la obsesión por los elementos ideológicos de la comedia deriva a menudo en aplicación irrelevante de estas cuestiones a comedias en las que nada de ello se trata» ${ }^{10}$. Es por esto por lo que quiero analizar detenidamente estos códigos y recalcar algunos de los muchos elementos astro-mitológicos de La vida es sueño y su relación con la figura del rey Felipe IV ${ }^{11}$.

\section{EL HIPOGRIFO}

Los elementos astro-mitológicos en La vida es sueño son tan densos y complejos que necesitamos un tipo de vehículo para adentrarnos en este confuso laberinto. Una manera de penetrar los intersticios del texto nos la presenta Calderón con la primera palabra de la obra: hipogrifo. Como bien ha explicado Jorge Luis Borges, esta criatura significa la imposibilidad y la incongruencia. Así Virgilio hablaba de la imposibilidad de unir caballos y grifos. Cuatro siglos después, Servio, comentando la obra virgiliana, añadía que los caballos detestaban a los grifos. De ahí que Ludovico Ariosto imaginara este imposible en el hipogrifo de su Orlando furioso. Críticos tales como Bruce Wardropper, Margaret Maurin, Ángel Cilveti y Cesáreo Bandera han estudiado el

${ }^{9}$ Para McKendrick (1974): «The Spanish theatre no less than the English was a potential arena for subversion - moral, religious, political. This is why it was licensed and censored, this is why it was attacked and opposed» (p. 107). Por esto se necesitaban técnicas especiales para obtener un decir sin decir: «Techniques of distancing and distortion defused criticism but simultaneously allowed it to be made» ( $\mathrm{p}$. 108). Esta es la cortesía o decoro expresada por el dramaturgo (p. 122). Claro que hay mucha discusión sobre el significado de las críticas veladas. Ver su discusión de La estrella de Sevilla (pp. 164-165).

${ }^{10}$ Arellano, 2005, p. 117.

${ }^{11}$ Agradezco a Luis Iglesias Feijoo y a Santiago Fernández Mosquera la invitación a presentar este estudio en el seminario calderoniano en la Universidad de Santiago de Compostela. Así he podido llegar a esta re-estructuración de mis acercamientos sobre esta obra. 
posible significado de este animal híbrido en la obra ${ }^{12}$. Roberto González Echevarría nos dice que el lenguaje del drama apunta a la creación de un arte monstruo ${ }^{13}$. El hipogrifo es entonces parte de este proceso, de este arte monstruo. Y, recordemos que ya Lope de Vega, en su Arte nuevo de hacer comedias había descrito la comedia nueva, con la fusión de opuestos (elementos trágicos y cómicos) como algo monstruoso. Lo irónico es que Lope de Vega rechaza el término hipogrifo ${ }^{14}$.

En el mismo Arte nuevo Lope incluye una lista de "vocablos exquisitos $»^{15}$ : la fabulosa isla de Pancaya, el río Metauro, los Semones o semidioses y el hipogrifo ${ }^{16}$. Lope también se burla del hipogrifo en una epístola "Al contador Gaspar de Barrionuevo» donde rechaza imágenes en las que los poetas "por lo hinchando se desvelan»:

\author{
Son todos sus caballos hipogrifos \\ perlifican el alba, el día estofan \\ con tarjetas, florones y anaglifos. (p. 233)
}

Aunque el hipogrifo se aúna al arte monstruo de Lope, es paradójicamente un grito de oposición a su teatro, y un signo que declara una nueva estética. Si el joven Calderón muestra antagonismo contra Lope,

12 Para Wardropper el hipogrifo es símbolo del parto, del nacimiento en este mundo; y Margaret Maurin relaciona el hipogrifo como monstruo con Rosaura y Segismundo. Bandera explica que el hipogrifo es «símbolo del orbis terrarum pues está compuesto de los cuatro elementos del universo, que, con la violencia de la caída, se agitan y revuelven en caótica confusión». Son los mismos signos que vemos en el horóscopo (1967, p. 188). Ángel Cilveti trata de rescatar el hipogrifo de su monstruosidad y proclama: «el hipogrifo es el símbolo unitario de la sexualidad masculina y femenina y de su connotación moral correspondiente» (1971, p. 165).

13 «Calderón fija su atención en los desaciertos, en los accidentes, en el proceso hacia una posible perfección, no en la perfección misma» (González Echevarría, 1982, p. 42). Según González Echevarría, aunque parece que tenemos un restablecimiento del orden al fin de la obra, "el vestuario de los personajes lo contradice» (p. 52). Tenemos a un Segismundo coronado pero vestido de monstruo: «La vida es sueño no resuelve la contradicción porque el arte de Calderón es un arte-monstruo, en el que los diferentes códigos teatrales con frecuencia están en desacuerdo» (p. 52).

${ }^{14}$ Ver mis estudios «The Critical Tower» (1993) y «The Hippogryph Wars» (1998) donde analizo la importancia de este vocablo en el teatro de la época. Sobre el tema hay un ensayo reciente de Güntert.

15 Rozas, 1976, pp. 189-190.
16 Morel-Fatio, 1901, p. 396. 
también muestra cierta continuidad con la obra de Ariosto. Veremos como el hipogrifo no solo revela un misterio político-mitológico derivado del Orlando furioso, sino que también el animal, como ya mencionamos, sirve de vehículo en el cual podemos hacer una travesía por los tres núcleos fundamentales de la mitología de La vida es sueño.

El hipogrifo es monstruo de composición triple. En primer lugar, une el caballo con el legendario grifo; pero este al mismo tiempo se compone de león y águila. Estos tres animales representan tres mitos en la obra, y así dividen este estudio en tres partes. En la primera parte estudiaremos brevemente al caballo en relación con Rosaura y el mito de Astrea. En la segunda veremos cómo el león se asocia con Segismundo y con el mito de Hércules. El tercer núcleo está representado por el águila, ave de Júpiter y segunda manifestación de Segismundo. En este tercer núcleo regresamos a la oposición Lope-Calderón que se inscribe en la obra en la oposición Saturno (Lope) Júpiter (Calderón).Y concluiremos con una mirada a los cielos por donde vuela el hipogrifo y donde, según Calderón:

\author{
En cuadernos de zafiro, \\ escribe con líneas de oro \\ en caracteres distintos \\ el cielo nuestros sucesos. (vv. 635-639)
}

\title{
2. Caballo/Rosaura/Astrea
}

El hipogrifo, como ha demostrado Wilson, sirve para mostrar la confusión de los elementos en un mundo que mostraría el pecado original del ser humano según la tradición cristiana o la concepción de una Edad de Hierro según las nociones greco-latinas ${ }^{17}$. En ambos casos nos encontramos con espacios y tiempos apartados del paraíso y de la Edad de Oro. Al caer Rosaura del caballo que ella llama hipogrifo tenemos esa caída del ser humano a un mundo oscuro, sin la presencia directa de dios o dioses. Pero, ¿por qué se refiere Rosaura a un animal mitológico que puede volar en el momento en que ella cae del caballo? En el Orlando Furioso el hipogrifo tiene un papel importante ya que es utilizado por Astolfo en sus viajes aéreos por todo

17 Wilson, 1936. 
el mundo.Y en nuestra comedia también tenemos un Astolfo. A causa de Astolfo se precipita Rosaura hacia Polonia, pues el príncipe de Moscovia la ha deshonrado y ella viene a solucionar la situación, vestida de hombre. Vemos, pues, una oposición: mientras que en la obra de Ariosto el hipogrifo nos lleva a regiones más altas, aquí es imagen de la caída de Rosaura, y bien sabemos que la caída del caballo es imagen de la falta de control en las pasiones ${ }^{18}$.

Hay un segundo elemento que aclara la clave astro-mitológica de la escena calderoniana. En el poema de Ariosto, Astolfo escucha la profecía de Andrónica de la llegada de una nueva Edad de Oro con el emperador Carlos $\mathrm{V}^{19}$. La mención de Astrea en Ariosto y en el segundo acto de La vida es sueño, cuando Rosaura toma este nombre en la corte, fija tal asociación. Recordemos que Astrea es la diosa de la verdad y de la justicia que dejó el mundo cuando declinaron las edades. Pasa de la ciudad al monte, luego a la montaña y finalmente a los cielos en los momentos que pasamos de la Edad de Oro a las de Plata, Cobre y Hierro. En los espacios ultraterrenos espera como la constelación Virgo el momento más oscuro de la edad de hierro para regresar al mundo. La escena de capa y espada tan desdeñada por parte de la crítica sirve para mostrar el verdadero rol de Rosaura en la obra. Su nombre es anagrama de "auroras», o sea que ella representa la aurora, el comienzo de la edad de oro con un nuevo rey.

La triple caída de Rosaura: engaño/deshonra, caída del caballo, y bajada del monte a Polonia (que yace en la oscuridad) puede muy bien recordar el retorno de Astrea, que viene de las estrellas a un mundo sumido en una nocturna y opaca confusión para rescatarlo a través de un nuevo príncipe que regirá con justicia. Y ¿qué mejor disfraz para la diosa Virgo/Astrea que la de una dama deshonrada? En el discurso sobre la Edad de Oro en el Quijote el caballero andante se lamenta de la «amorosa pestilencia» donde la mujer siempre es engañada por el hombre en la Edad de Hierro «aunque la oculte y cierre otro nuevo laberinto como el de Creta» (p. 157). Precisamente a un tal labe-

18 Comenzando con Platón y continuando con la Biblia, la falta de control sobre el caballo y la caída del caballo «representa al alma humana en estado de turbación cuando el pensamiento del deseo embaraza el recto raciocinio" (Valbuena Briones, 1962, p. 75).

19 Canto XV, vv. 35 y ss. 
rinto llega Rosaura cuando cae en Polonia y mira a Segismundo en su torre "monstruo de su laberinto» (v. 140).

Este encuentro de Rosaura y Segismundo revela no solo el paralelo entre estos dos seres infelices que son parte del caos del mundo, sino también el comienzo de la transformación de Segismundo a través de Rosaura. Mientras que el hipogrifo de Rosaura está formado de cuatro elementos a los que les faltan sus cualidades esenciales (representando un momento y una edad falta de armonía), parece como si Segismundo en su primer monólogo hablase del equilibrio de los cuatro elementos listados por Empédocles como fundamentos del cosmos. Lamentándose de su falta de libertad, Segismundo usa como ejemplos el ave (v. 123) —aire-, el bruto (v. 133) — tierra- y el pez (v. 143) —agua. Aunque se queja de su situación parece que habla de la armonía del cosmos a través de los elementos. Pero no es así, pues crea otro paralelo con Rosaura cuando rompe la cuaternidad ${ }^{20}$. En su monólogo, Segismundo establece un desdoblamiento del tercer elemento, del agua, pues añade a la estrofa sobre la libertad del pez una segunda décima donde imagina que: «Nace el arroyo, culebra / que entre flores se desata / y apenas, sierpe de plata...» (vv. 153-155). No solo imagina Segismundo a este riachuelo como culebra sino también como sierpe. De esta manera no solo el agua se desdobla sino también la serpiente, lo que nos recuerda el rol de esta en el mito de la tentación y caída del paraíso. El hecho de un doble desdoblamiento amplifica la significación del número dos, que según la numerología renacentista significa la falta de unidad, lo triste y desafortunado. Para Cornelio Agrippa, el dos es el número del diablo, la falta de armonía ${ }^{21}$. $\mathrm{Y}$ es justamente entonces cuando llegamos al último elemento evocado por Segismundo, el fuego, el volcán Etna (v. 164) que representa la cólera del príncipe encarcelado, la falta de eucrasia en sus pasiones. El Etna evoca también el mundo demoníaco ${ }^{22}$. Este exceso,

20 Sobre la importancia de las pasiones junto con el estilo en el monólogo de Segismundo, puede verse el artículo de Gerli (1983).

21 «The number of two is a number of uncleanness, and it is most unhappy in their Soothsayings... for these two are accounted by the Astrologers unfortunate. Pythagoras sayd... that Duality was a Divell, and an evill intellect» (Agrippa, Three Books, p. 178).

22 Para Javier Herrero, este volcán evoca el «caos cósmico» y muestra cómo el fuego volcánico le pertenece al diablo» (1982, p. 81). 
esta discrasia de humores y elementos proviene de la falta de justicia, como vemos en el verso 167 y por eso desciende a Polonia Rosaura/Astrea. Vemos pues cómo desde un principio, Calderón crea un trenzado de imágenes cristianas y paganas - con Astrea, diosa pagana que en interpretaciones cristianas de la cuarta égloga de Virgilio, es la Virgen María y con un mundo oscuro que puede representar o la Edad de Hierro o el mundo después de la caída, siendo también Rosaura una nueva Eva.

La crítica se ha preguntado por qué no se casan Rosaura y Segismundo al final de la obra. Pero para Calderón, Rosaura pertenece a Astolfo, quien la había evocado como Astrea en Ariosto. La diosa o la virgen ha venido al mundo para servir de guía y apoyo. Es el casamiento de Rosaura con Astolfo lo que vuelve a evocar la profecía ariostesca y borrar la deshonra en el texto calderoniano. Y, al refrenar sus pasiones puede Segismundo ser percibido como el príncipe equilibrado cuya justicia matrimonial y perdón del padre muestra su nueva sabiduría y clemencia.

Vemos claramente la transformación de Rosaura y de Segismundo cuando aparece ella montada a caballo en el tercer acto. Ya no hay hipogrifo ni caída ni disfraz. Ella resueltamente controla el caballo de las pasiones, descrito, al igual que el hipogrifo, a través de los cuatro elementos («monstruo es de fuego, tierra, mar y viento»). Además, le ruega a Segismundo que haga lo mismo convirtiéndose en príncipe perfecto, representante del sol:

\author{
Generoso Segismundo, \\ cuya majestad heroica \\ sale al día de sus hechos \\ de la noche de sus sombras \\ y como el mayor planeta \\ que en los brazos de la aurora \\ se restituye luciente $[\ldots]$ \\ así amanezcas al mundo \\ luciente sol de Polonia (vv. 2690-2696; 2702-2703)
}

De esta manera, el cruel parece haberse convertido en generoso, el encarcelado en príncipe que va a traer consigo la aurora, el nuevo día a Polonia, mientras que Rosaura, con autodominio y compartiendo 
las cualidades de Astrea, inspira a Segismundo esta generosidad, luminosidad y justicia.

Todo esto no es nada ajeno a lo que estaba ocurriendo en España en el momento en que se escribió la obra. Debemos recordar que la alabanza de los Habsburgos a través de la astro-mitología incluía la noción que estos descendían directamente de Apolo por mediación de los emperadores romanos y Eneas. Cada nuevo rey era identificado con el sol que debía iluminar a la cristiandad ${ }^{23}$. Felipe IV fue llamado el «rey planeta» y comparaciones de su majestad con el sol abundaban en la poesía del momento. El privado del rey, el CondeDuque de Olivares se encargó de realzarla ${ }^{24}$. Recordemos que el sol era el cuarto planeta tolemaico, y coincidía de esta manera con el cuarto Felipe.Y no olvidemos que la figura de Astrea también fue de gran importancia para engalanar el reinado de Felipe. Ya en 1622, durante el segundo año de su reinado, el conde de Villamediana representó en una comedia ante el monarca el descenso de la diosa de la Edad de Oro sobre un águila. Me parece más que claro que esta obra calderoniana esboza un contexto político bajo imágenes astro-mitológicas: la edad de oro en Virgo/Astrea, la justicia con Libra, y la monarquía con el sol.

\section{León/Segismundo/HérCules}

Ya en este primer acto de La vida es sueño, encontramos a Segismundo «vestido de pieles» (p. 90) y con «membrudos brazos» (v. 184), lo que recuerda la representación emblemática de Hércules, que tenía gran fuerza en sus brazos y se vestía de piel de león, recalcando su victoria sobre el león de Nemea. Para Enrique de Villena, quien escribió un tomo sobre las labores de Hércules, esta labor sirve para «reprehender los soberbios que en la naturaleza del león son entendidos» ${ }^{25}$. Y, ya sabemos que la prueba de Segismundo en palacio servirá para determinar si ha podido conquistar su propia «ambición y sober-

23 Por ejemplo, el sol se representaba como Apolo y el Iam Illustrabit Omnia de Felipe II, el ave Fénix, o el Futurus Alter Sol con que se alabó a Felipe III (Tanner, 1993, p. 239).

24 Brown y Elliott, 1980, p. 188.

${ }^{25}$ Villena, Los doce trabajos de Hércules, p. 28. 
bia» (v. 1051) despertada por Clotaldo - lo interesante es que es una prueba falsa, ya que el príncipe nunca ha podido experimentar la prudencia que, según las teorías de la época, ayudaba a controlar esta ambición ${ }^{26}$. Recordemos además que el león era considerado «rey» de los animales. Segismundo debe ser rey, pero reprimir, como ser humano, los excesos del león. La metáfora de rey o príncipe como león no es nada nueva - aún la encontramos en Maquiavelo ${ }^{27}$. Lo nuevo aquí es que Segismundo está sumido en la naturaleza animal en su encarcelamiento.

Esta visión de Segismundo como Hércules puede verse también en el sueño profético que tiene la madre de Segismundo, Clorilene, sobre su nacimiento. Aquí se nos presenta al recién nacido como una víbora que mata a su propia madre (v. 675). Al igual que con la deshonrada Rosaura que representa a Virgo/Astrea, tenemos un mito desplazado, al inverso de lo que debe de ser. El nacimiento de Hércules al igual que el de Segismundo, se relaciona con una culebra. Hércules, hijo de Alcmena y de Júpiter disfrazado, es amenazado por los celos de la esposa de Júpiter, Juno, quien manda un par de culebras a su cuna para que maten al niño. Este es el primer triunfo de Hércules, quien destruye las culebras. En Calderón la inversión del mito, la muerte de la culebra, profetiza la muerte de la madre. Además, la víbora en su contexto emblemático significa la crueldad del hijo y su falta de legitimidad, pues se decía que amores ilegítimos llevaban al nacimiento de un monstruo y Segismundo se describe como «mons-

26 Estudiando la figura de Segismundo, Pring Mill muestra cómo va a fallar la prueba que le ha impuesto su padre en palacio, pues según Santo Tomás de Aquino «la prudencia no es jamás innata» (1970, p. 62), sino que se adquiere con la experiencia.Ver también el trabajo de J. B. Hall sobre la soberbia en la obra. Para este crítico, uno de los elementos más importantes es la lección de que el ser humano tiene tendencia a «misinterpret reality as a result of pride» (1982, p. 347).

27 Recordemos la famosa imagen en el Príncipe (cap. 18) donde el soberano debe actuar como león y zorro. Cuando Maquiavelo explica que el príncipe debe actuar como hombre y bestia, recordamos inmediatamente a Segismundo. Basándose en el castigo del soldado rebelde, H. B. Hall afirma que al final de la obra Segismundo es un príncipe maquiavélico ("calculating, cruel, Machiavellian»1968, p. 197). Arellano rechaza tales acercamientos, aboga por la sinceridad del príncipe y asegura que «Segismundo no acepta el juego para conservar su status» (2001, p. 78). 
truo en forma de hombre» (v. 672) ${ }^{28}$. Segismundo va a tener que sobreponerse a su naturaleza de víbora, la violencia que él significa, para convertirse en el príncipe perfecto - $y$ recordemos que esta violencia aparece ya en el primer acto cuando trata de matar a Rosaura (v. 180). Ya que puede refrenar su condición (v. 240) al ver y escuchar a Rosaura, nos damos cuenta de que ella es en realidad una figura que le sirve de guía y de medio para su transformación. Como dice ella al enfrentarse a Segismundo: "hoy el cielo me ha guiado» (v. 247).

Al transformarse, Segismundo pasa de ser víbora, león y Hércules, a ser águila y Júpiter. Pero antes de comenzar un nuevo apartado debemos recordar la importancia de Hércules para el aparato laudatorio de los reyes españoles. Recordemos que el Hércules mitológico supuestamente pasó por casi toda Europa, dejando hijos que crearon genealogías monárquicas. En España triunfó en uno de sus mayores trabajos, la captura del ganado de Gerión. De esta manera, se le considera fundador de la línea real. Carlos V utilizó como símbolo de su imperio el emblema de las columnas de Hércules, cambiándole su significado $^{29}$. Felipe II también se deleitó con esta imagen mitológica poseyendo una serie de tapices sobre los trabajos de Hércules ${ }^{30}$.Y cuando Felipe IV subió al trono, la ciudad de Sevilla preparó una medalla conmemorativa con la figura del rey por un lado y con el niño Hércules matando culebras en el otro. No debe pues sorprendernos que Francisco de Zurbarán recibiera una comisión en 1634 para pintar los trabajos de Hércules en el palacio del Buen Retiro, como alabanza a Felipe IV.

En La vida es sueño hemos visto que la representación del rey como Hércules es algo problemática. En vez de matar a las culebras enviadas por Juno, se convierte en el viborezno que mata a su madre durante el parto. También lleva las pieles de Hércules, que representan el tri-

${ }^{28}$ Juan Francisco de Villava, por ejemplo, en sus Empresas espirituales y morales acusa a los viboreznos de «traidores» pues matan a la madre: «Le dais la muerte porque os dio la vida" (fol. 49).

${ }^{29}$ Según Brown y Elliott: «The invention of the emperor's emblematic device, which was designed around the mythical columns of Hercules, fixed the association of the ancient hero with the modern ruler firmly in the minds of sixteenth century princes» (1980, p. 157). Recordemos que cambió el lema de non plus ultra a plus ultra, para significar que se debía ir más allá del Mediterráneo y conquistar tierras.

30 Brown y Elliott, 1980 , p. 273 , nota 39. 
unfo sobre el león de Nemea - pero cabe preguntarse si Segismundo triunfa sobre la bestia, la monstruosidad de su ser.Aunque parece haber una clara transformación de víbora/león en águila, el texto incluye la rebelión del príncipe contra el rey y sus intentos de controlar sus pasiones. Estos elementos reflejan la situación histórica en España. Sabemos que hubo graves tensiones entre Felipe III y su hijo antes de que éste heredara el trono. Y, al igual que Hércules muchas veces no pudo controlar sus pasiones, el joven Felipe IV era muy bien conocido por sus muchos amoríos ${ }^{31}$.

\section{4. Águila/Segismundo/JúPITER}

En La vida es sueño vislumbramos, entonces, la transformación de una figura monstruosa en un supuesto príncipe perfecto ${ }^{32}$. Pero hay muchas ambigüedades en el texto que nos permiten pensar que la bestia todavía se esconde bajo una vestimenta civilizada. Tampoco sabemos si la obra fue escrita para representar el triunfo de Felipe IV o simplemente sirve para continuar la educación del príncipe. Para conquistar su naturaleza terrestre de culebra o víbora, Segismundo tiene que utilizar la naturaleza opuesta. Recordemos que el segundo sueño en la comedia tiene que ver con el águila que pasa por el aire y el fuego - y el águila es la tercera parte del híbrido hipogrifo (vv. 1034 y ss. $)^{33}$. La culebra entonces es una criatura de suplemento, no

${ }^{31}$ Recordemos que Hércules se vistió de mujer al estar tan apasionado por Onfale; y que dejó la misión heroica de los Argonautas al enamorarse del bello joven Hylas. Sobre los amoríos de Felipe IV, escribe Elliott que el Conde-Duque de Olivares: "was reported to be accompanying the king on nocturnal expeditions... encouraging the king in "illicit affairs"» (1986, p. 112). Y John Lynch afirma que su "passion for women... turned him into a jaded voluptuary well before middle age» (1981, p. 68).

32 Así como la primera parte de las obras de Calderón comienza con una comedia que trata de las vicisitudes de un príncipe, también concluye de esta manera. La última obra, la comedia número doce de la primera parte es El príncipe constante. La cuarta obra también trata de este tema e incluye la figura de Astrea: La gran Cenobia. Hay en esta parte comedias religiosas como la tercera, El purgatorio de San Patricio y la quinta, La devoción de la cruz y comedias de capa y espada como la segunda, Casa con dos puertas, la novena, La dama duende y la décima, Peor está que estaba. También hay crónicas históricas como la oncena obra: El sitio de Bredá.

33 Sobre los sueños en la obra ver a Hesse, 1967 (quien utiliza las teorías junguianas del subconsciente), Julian Palley, 1976 (quien utiliza un acercamiento freu- 
pertenece al hipogrifo, es simplemente algo soñado por Clorilene (o algo inventado por Basilio, quien parece tener sospechas de la fidelidad de Clorilene). Si Segismundo es hijo ilegítimo, tenemos una relación más estrecha entre este y Rosaura, que también nace de relación ilegítima ${ }^{34}$. Esto nos podría llevar a especular que el padre de Rosaura y de Segismundo es la misma persona - Clotaldo. Su nombre viene de "Cloto» que es una de las tres parcas quien como hilandera teje los hilos de la vida- que es lo que hace Clotaldo ${ }^{35}$.

La unión de estas dos criaturas en los sueños, es decir, el águila y la serpiente, tiene dimensiones míticas. Según Witkower:

Fights between eagles and snakes have actually been observed... The greatness of the combat gave the event an almost cosmic significance. Ever since, when man has tried to express a struggle or a victory of cosmic grandeur, the early memory of this event has been evoked ${ }^{36}$.

Ya que el águila se asocia con el sol y con los monarcas solares, el águila que vence a la serpiente se convierte en figura emblemática de los reyes durante la Edad Media y el Renacimiento ${ }^{37}$. Es esto lo que parece hacer Segismundo - vencer la culebra y convertirse en verdadero rey.

Ya hemos visto cómo el águila baja de los cielos en una comedia de espectáculo de Villamediana, trayendo consigo a Astrea, para que acompañe al rey, Felipe IV. En La vida es sueño, el águila no solo evoca el triunfo final del príncipe convertido en héroe solar, sino que recuerda que uno de los emblemas de los Habsburgos es el águila con dos cabezas. Pero el águila también es el ave de Júpiter, y en la obra calderoniana tenemos un gran conflicto entre padre e hijo que provie-

diano a las relaciones padre-hijo), y De Armas, 1986a, donde presento uno de mis primeros acercamientos al texto desde el punto de vista emblemático y astrológico (pp. 108-138).

34 Sobre la posibilidad del incesto ver a Honig, 1972, p. 161; De Armas, 1986a, p. 91 y Anthony (El Saffar), 1993, p. 173.

${ }^{35} \mathrm{Si}$ esto es cierto tenemos como en La gloria de Niquea y La dama duende una velada alusión al incesto entre hermano y hermana.

36 Witkower, 1977, p. 18.

37 Witkower, 1977, p. 43. 
ne de la lucha cósmica entre Saturno y Júpiter ${ }^{38}$. No quiero aquí estudiar en detalle estos bien conocidos elementos ${ }^{39}$. Brevemente recordemos los tres elementos claves del mito: (1) la profecía que el hijo le quitaría el trono a su padre Cronos/Saturno; (2) la decisión del padre de deshacerse del hijo; y (3) la venganza del hijo en una guerra que dura diez años y cuyo fin es la caída de Saturno de los cielos. En La vida es sueño se presentan los mismos elementos, con dos cambios principales: en vez de comerse a su hijo, Basilio lo encarcela y a pesar de ganar la batalla, Segismundo se humilla frente al padre. Este final nos lleva a algo que esbozamos al principio, ya que la obra puede leerse como lucha monárquica o como conflicto literario. Si pensamos en esta segunda interpretación, Júpiter (Calderón) "perdona» al padre (Lope de Vega). Aunque en esta comedia tenemos el nuevo arte monstruo de Calderón, se acepta que sus orígenes provienen de Lope. El hijo en su ansiedad de influencia no tiene que destruir al padre. Pero esta segunda interpretación no tiene tantos niveles de especificidad como la visión política, el triunfo de Felipe IV junto con un «decir sin decir» que cuestiona la imagen del príncipe perfecto acompañado de Astrea, del águila del imperio y del valor de Hércules.

Para ahondar en esta problemática debemos revisar el conflicto Saturno-Júpiter a través de la astrología y así ver también la dificultad de Felipe en convertirse en el astro-mitológico rey planeta.

\section{Cuadernos de Zafiro}

El águila que vuela hasta el más alto de los elementos, el fuego, y el hipogrifo que bate sus alas en la región del aire en Ariosto ${ }^{40}$, nos llevan al último apartado, a la influencia de los astros en la obra y su relación con mitos y momentos históricos. Recordemos que el primer elemento del mito Saturno-Júpiter, la profecía, entra en el texto calde-

38 Para Ruiz Ramón, 1990, es Urano en vez de Cronos/Saturno, el dios mitológico más importante en el conflicto entre padre e hijo. Este crítico propone una lectura uraniana en vez de la edipiana.

${ }^{39}$ Ver De Armas, 1986 b.

40 El hipogrifo fue capturado y domado por Atlas quien lo monta. Luego, es Ruggiero su dueño y finalmente Astolfo. Hacia el fin de la obra, Canto 44, una vez que llegan a Provence, Astolfo libera al hipogrifo siguiendo el mandato de San Juan. 
roniano para mostrar claramente la relación de Basilio con Saturno. Al hablar este de la presencia nociva de «mísero» y «mortal» planeta (v. 700) y del "planeta más impío» (v. 789) que aflige a su hijo, está refiriéndose a Saturno, que en la astrología de la época era el más maléfico de los astros. Y, en realidad, Basilio está aquí evocando su propia influencia. Al encarcelar a Segismundo para prevenir los efectos de la profecía está en realidad siguiendo los pasos de Saturno que es el planeta que indica encarcelamientos. Y sabemos además que Saturno es el planeta del conocimiento oculto y de la sabiduría, elementos implicados en la relación Basilio-Segismundo ${ }^{41}$. El mito cósmico se ha convertido en elemento astrológico. Deberíamos preguntarnos el porqué de tal transformación.

Pocos años antes del nacimiento del futuro Felipe IV, Tommaso Campanella, obsesionado por la creación de un imperio platónico perfecto que vendría antes del fin del mundo, formó parte de una rebelión en el virreinato español de Nápoles. Fue parte de este complot ya que según los astrólogos, el gobierno cambiaría en 1600. Lo que cambió fue su destino, pues fue arrestado y encarcelado desde 1602 hasta $1632^{42}$. En la cárcel escribió muchas de sus más famosas obras, incluyendo De monarchia hispanica donde el nuevo estado ideal ya no sería creado por Calabria, sino por los españoles. Explica Anthony Pagden que Campanella nunca dudó de sus ideales. Solamente transformó el vehículo que usaría la divinidad para traer al mundo la perfección: primero Calabria, luego España, y después Francia adonde se escapó (p. 44). Lo que nos interesa de su tratado sobre España son dos cosas: primero, su alabanza de la prudencia del rey (algo que Segismundo tiene que adquirir), y segundo el hecho de que para él, la conjunción de Saturno y Júpiter en el signo de Sagitario (signo de España) en el año 1603 indica que pronto llegará la Edad de Oro, la monarquía universal española que él profetiza.

Las nociones de Campanella parecen haberse difundido por toda Europa $^{43}$, y fueron recordadas por Aldrete de Soto en su Discurso de la cometa de 1682:

${ }^{41}$ Klibansky et al., 1964, pp. 130-131.

42 Pagden, 1990, p. 43.

43 Según Méchoulan, 1991, p. 127, las profecías de Campanella sobre la monarquía universal española ya circulaban en España en la segunda década del diecisiete. 
Y no es nuevo en la astrología que cometas y estrellas nuevas signifiquen nacimientos de monarcas grandes; pues en el año 1604 apareció una estrella cometa en el signo de Sagitario, que predomina en España y por ella juzgó el doctísimo Campanela y otros astrólogos de aquel tiempo, el nacimiento de la majestad del señor rey don Felipe Cuarto el Grande ${ }^{44}$

Aunque aquí confunde Aldrete la nova de 1604 con la conjunción, no cabe duda que toda una serie de eventos astrológicos predicen el nacimiento de un gran monarca ${ }^{45}$.

Quisiera concluir con un segundo evento. En 1605, año del nacimiento de Felipe IV, ocurren tres eclipses. El famoso eclipse solar del 2 de octubre de 1605 fue precedido por dos eclipses de la luna el mismo año (23 de marzo y 17 de septiembre). Según los tratados astrológicos, estos incluyen como efectos: la traición, las enemistades entre hermanos y la caída de un rey. No cabe duda, pues, de la relación entre estos eventos y los conflictos de La vida es sueño. Y, para subrayar la clave político-astrológica, escribe Calderón:

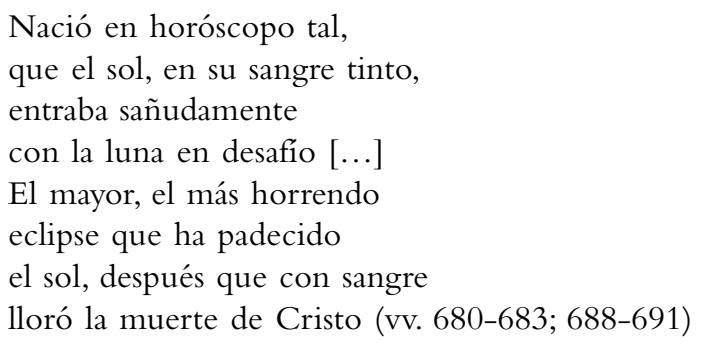

Este terrible eclipse, que utiliza Shakespeare para su King Lear, es el mismo al que se refiere Calderón, apuntando al nacimiento del futuro Felipe $\mathrm{IV}^{46}$. La referencia al eclipse que surgió a la muerte de Cristo no es fortuita. Nace el príncipe español un viernes santo, día

Aparecen en Juan de la Puente, Coveniencia de las dos monarquías (1612) y en Juan de Salazar, La política española (1619). En La monarquía hispánica Campanella escribe: «Pero el eclipse y la gran confluencia en Sagitario, signo que es de España, revelará muchos secretos, que diré cuando me llegue el momento de hablar de ello» (p. 26).

${ }^{44}$ Citado en Hurtado Torres, 1984, p. 110).

45 Sobre la nova de 1604 ver De Armas, 1986a, pp. 117-122, y 2001.

46 Sobre el paralelo entre estos dos eclipses ver De Armas, 2001 y 2006. 
en que se conmemora este evento ${ }^{47}$. Así, el día de su nacimiento junto con la presencia de un eclipse, es causa de augurios y presagios.

Unos veinticinco o treinta años después de estos eventos celestes, Calderón escribe La vida es sueño cuya clave astro-mitológica tiene que ver con los mitos laudatorios del comienzo del reinado de Felipe IV y con los eventos astrológicos que profetizan su nacimiento. Si seguimos a Campanella, vemos a Felipe/Segismundo como príncipe perfecto, un nuevo Júpiter, acompañado de la diosa de la Edad de Oro, Astrea. Es rey planeta que ilumina con su ser al imperio español y trae consigo la república platónica. Pero, la conjunción Júpiter-Saturno puede profetizar un monarca universal según Campanella, o simplemente un cambio drástico en el gobierno o en la religión según Albumazar ${ }^{48}$.

Y, si añadimos a todo esto que el sol, en el año del nacimiento de Felipe/Segismundo sufrió un grave eclipse, podríamos pensar que se le oscurece y minimiza el poder al futuro rey, cuyo momento natal es un viernes santo que recuerda la muerte de Cristo. Todas estas claves astro-mitológicas pueden contener un «decir sin decir». Sí, hay aquí una alabanza de la monarquía, pero hay también un cuestionamiento de nociones triunfalistas. La obra puede estudiarse como alabanza al rey sol o meditación sobre su luminosidad veinticinco o treinta años después de su nacimiento. Los papeles de zafiro y los folios de Calderón guardan intrincados dibujos del hado cuyos significados deben leerse con la nueva prudencia (si es que la tiene) del desastrado y afortunado príncipe Segismundo.

47 Cervantes en La gitanilla se refiere al nacimiento de Felipe IV en viernes santo. En procesión a la iglesia van Felipe III y su esposa Margarita seguidos de su hija Ana de Austria. Tras ellos va el Lucero o príncipe recién nacido, que ha nacido en día de tristeza: «A sus espaldas le sigue / un Lucero que a deshora / salió, la noche del día / que el cielo y la tierra lloran» (ed. Avalle-Arce, vol. I, p. 80).

48 Las teorías de Albumazar, astrólogo de Bagdad del siglo noveno, fueron muy conocidas en Europa durante la Edad Media y el Renacimiento. En España, Lope de Vega alude a su obra en varias de sus comedias y lo incluye como personaje en una de ellas. Para Albumazar las conjunciones de Saturno y Júpiter son claves de grandes cambios o en la política o en la religión. 


\section{Bibliografía}

Agrippa, C., Three Books of Occult Philosophy, London, Chthonios Books, 1986. Anthony (El Saffar), R., "Violante: The Place of Rejection», en The Prince in the Tower. Perceptions of "La vida es sueño", ed. F. A. de Armas, Lewisburg, Bucknell University Press, 1993, pp. 165-182.

Arellano, I., Calderón y su escuela dramática, Madrid, Laberinto, 2001.

- Historia del teatro español del siglo XVII, Madrid, Cátedra, 2005.

Bances Candamo, F., Teatro de los teatros de los pasados y presentes siglos, ed. D. Moir, London, Támesis, 1970.

Bandera, C., Mimesis conflictiva, Madrid, Gredos, 1975.

BORCHARD, K., «Traducción y reescritura: cambios problemáticos en la traducción de Edward FitzGerald de La vida es sueño", Didascalia, 1, 2004, Suplemento, http://www.didascalia.com.br/index2.htm.

Brown, J. y J. H. Elliott, A Palace for a King: The Buen Retiro and the Court of Philip IV, New Haven, Yale University Press, 1980.

Calderón de la Barca, P., La vida es sueño, ed. C. Morón, Madrid, Cátedra, 1998.

Campanella, T., La monarquía hispánica, ed. P. Mariño, Madrid, Centro de Estudios Constitucionales, 1982.

Cervantes, M., El ingenioso hidalgo don Quijote de la Mancha, ed. L. A. Murillo, Madrid, Cátedra, 1978, 2 vols.

- Novelas ejemplares, ed. J. B. Avalle-Arce, Madrid, Castalia, 1982, 3 vols.

Cilveti, Á. L., El significado de "La vida es sueño», Valencia, Albatros, 1971.

Cope, J. I., "The Platonic Metamorphoses of Calderón's La vida es sueño», Modern Languages Notes, 86, 1971, pp. 225-241.

De Armas, F. A., The Return of Astraea. An Astral-Imperial Myth in Calderón, Lexington, University of Kentucky Press, 1986a.

— «El planeta más impío: Basilio's Role in La vida es sueño», Modern Language Review, 81, 1986b, pp. 900-911.

- «Rosaura Subdued:Victorian Readings of La vida es sueño», South Central Review, 4, 1987, pp. 43-62.

- "The Critical Tower», en The Prince in the Tower. Perceptions of "La vida es sueño», ed. F. A. de Armas, Lewisburg, Bucknell University Press, 1993, pp. 3-14.

- "The Hippogryph Wars: Lope de Vega, Claramonte and Calderón», en $A$ Society on Stage. Essays on Spanish Golden Age Drama, ed. E. H. Friedman, H. J. Manzari y D. D. Mille, New Orleans, University Press of the South, 1998, pp. 45-58.

- «Segismundo/Philip IV: The Politics of Astrology in La vida es sueño», Bulletin of the Comediantes, 53, 2001, pp. 83-100. 
- «El rey astrólogo en Lope de Vega y Calderón», en El teatro clásico español a través de sus monarcas, ed. L. García Lorenzo, Madrid, Fundamentos, 2006, pp. 119-134.

Elliot, J. H., The Count-duke of Olivares: The Statesman in an Age of Decline, New Haven, Yale University Press, 1986.

Gerli, M., «Forma interior y forma exterior del primer monólogo de Segismundo: la sistematización de la pasión», en Calderón. Actas del congreso internacional sobre Calderón y el teatro español del Siglo de Oro, ed. L. García Lorenzo, Madrid, CSIC, 1983, vol. III, pp. 1101-1108.

GonzÁlez EChEVArRíA, R., «El "monstruo de una especie y otra”: La vida es sueño, iii, 2, 725», en Calderón. Códigos, Monstruos, Icones. Co-textes, Montpellier, Centre d'études et recherches sociocritiques, 1982, pp. 5-25.

Greer, M., The Play of Power. Mythological Court Dramas of Calderón de la Barca, Princeton, Princeton University Press, 1991.

Güntert, G., «La vida es sueño: algo más sobre el hipogrifo violento», en Calderón 2000. Homenaje a Kurt Reichenberger en su 80 cumpleaños, ed. I. Arellano, Kassel, Edition Reichenberger, 2002, vol. 2, pp. 495-507.

Hall, H. B., «Segismundo and the Rebel Soldier», Bulletin of Hispanic Studies, 45, 1968, 189-200.

Hall, J. B., «The Problem of Pride and the Interpretation of Evidence in La vida es sueño», Modern Language Review, 77, 1982, pp. 339-347.

Herrero, J., «El volcán en el paraíso. El sistema icónico del teatro de Calderón», Co-textes, 3, 1982, pp. 59-113.

Hesse, E. W., «El motivo del sueño en La vida es sueño», Segismundo, 3, 1967, pp. 55-62.

Honig, E., Calderón and the Seizures of Honor, Cambridge, Harvard University Press, 1972.

Hurtado Torres, A., La astrología en la literatura del Siglo de Oro, Alicante, Instituto de Estudios Alicantinos, 1984.

Iglesias Feijoo, L., "En el texto de Calderón: La vida es sueño», en Calderón 2000. Homenaje a Kurt Reichenberger en su 80 cumpleaños, ed. I. Arellano, Kassel, Edition Reichenberger, 2002, pp. 517-532.

Klibansky, R., E. PanOfsky y F. SAXL, Saturn and Melancholy, London, Thomas Nelson, 1964.

LEÓN, P. R. «El caballo desbocado, símbolo de la pasión desordenada en la obra de Calderón», Romanische Forschungen, 95, 1983, pp. 23-35.

Lope de Vega Carpio, F., Obras poéticas, ed. J. M. Blecua, Barcelona, Planeta, 1969.

LynCH, J., Spain under the Habsburgs, New York \& London, Oxford University Press, 1981, vol. 1. 
Maspoch Bueno, S., "Los animales en La vida es sueño», en Pedro Calderón de la Barca. El teatro como representación y fusión de las artes, Anthropos Extraordinarios, 1, 1997, pp. 107-111.

Maurin, M., "The Monster, the Sepulcher and the Dark: Related Patterns of Imagery in La vida es sueño», Hispanic Review, 35, 1967, pp. 161-178.

McKendrick, M., Woman and Society in the Spanish Drama of the Golden Age: A Study of the "Mujer Varonil», London, Cambridge University Press, 1974.

- Playing the King. Lope de Vega and the Limits of Conformity, Woodbridge and Rochester, Tamesis, 2000.

MÉCHOUlan, H., «La critique de l'Espagne par Campanella à partir d'une réfutation manuscrite en français de sa Monarchie espagnole: La monarchie des nations», en L'Age d'Or de l'influence espagnole. La France et l'Espagne à l'époque d'Anne d'Autriche 1615-1666, ed. C. Mazouer, Mont-de-Marsan, Éditions InterUniversitaires, 1991, pp. 125-135.

Morel-Fatio, A., "L'Arte nuevo de hacer comedias en este tiempo de Lope de Vega», Bulletin Hispanique, 3, 1901, pp. 365-406.

RuAno de la Haza, J. M., La primera versión de "La vida es sueño» de Calderón, Liverpool, Liverpool University Press, 1992.

Menéndez Pelayo, M., Calderón y su teatro, Madrid, A. Pérez Dubrull, 1910. Pagden, A., Spanish Imperialism and the Political Imagination, New Haven and London, Yale University Press, 1990.

Palley, J., "Si fue mi maestro un sueño”: Segismundo's Dream», Kentucky Romance Quarterly, 23, 1976, pp. 149-162.

Pring-Mill, R. D. F., "Los calderonistas de habla inglesa y La vida es sueño: métodos de análisis temático-estructural», en Litterae Hispaniae et Lusitanae, ed. H. Flasche, München, Max Huber Verlag, 1968, pp. 369-413.

— «La "victoria del hado" en La vida es sueño", en Hacia Calderón. Coloquio anglogermano, ed. H. Flasche, Berlin, Walter de Gruyter, 1970, pp. 53-70.

Rozas, J. M., Significado y doctrina del "Arte nuevo» de Lope de Vega, Madrid, Sociedad General Española de Librerías, 1976.

Ruano, J. M., «Introducción», Pedro Calderón de la Barca, La vida es sueño, Madrid, Castalia, 1994.

Ruiz Ramón, F., «El mito de Uranus en La vida es sueño», en Teatro del Siglo de Oro: Homenaje a Alberto Navarro González, ed. V. García de la Concha, J. Canavaggio, T. Berchem, M. L. Lobato, Kassel, Reichenberger, 1990, pp. 547-562.

Sciacca, F., "Verdad y sueño de La vida es sueño de Calderón de la Barca», Clavileño, 1, 1950, pp. 1-9.

Sloman, A. E., "The Structure of Calderón's La vida es sueño», en Critical Essays on the Theater of Calderón, ed. B. W. Wardropper, New York, New York University Press, 1965, pp. 90-100. 
Sturm, H.G., «From Plato’s Cave to Segismundo’s Prison», Modern Language Notes, 89, 1974, pp. 280-289.

Tanner, M., The Last Descendant of Aeneas. The Hapsburgs and the Mythic Image of the Emperor, New Haven, Yale University Press, 1993.

Valbuena Briones, Á. J., «El simbolismo en el teatro de Calderón. La caída del caballo», Romanische Forschungen, 74, 1962, pp. 60-76.

Vega García-Luengos, G., «Ecos de Rosaura (para leer mejor el inicio de La vida es sueño e incrementar el repertorio calderoniano)", Criticón, 8789, 2003, pp. 887-898.

Villava, J. F., Empresas espirituales y morales, Baeza, Fernando Díaz de Montoya, 1613.

Villena, E., Los doce trabajos de Hércules, ed. M. Morreale, Madrid, Real Academia Española, 1958.

Wardropper, B., "Apenas llega cuando llega a penas», Modern Philology, 57, 1960, pp. 240-244.

Whitby, W. M., "Rosaura's Role in the Structure of La vida es sueño», en Critical Essays on the Theater of Calderón, ed. B. W. Wardropper, New York, New York University Press, 1965, pp. 101-113.

Wilson, E. M., "The Four Elements in the Imagery of Calderón», Modern Language Review, 31, 1936, pp. 34-47.

- "On La vida es sueño», Critical Essays on the Theater of Calderón, ed. B. W. Wardropper, New York, New York University Press, 1965, pp. 63-89.

Witkower, R., Allegory and the Migration of Symbols, New York, Thames and Hudson, 1977. 